Pablo Fuentes R., El melodrama ácrata Aires de la pampa de Víctor Domingo Silva y su articulación del tiempo según la utopía libertaria de Mijaíl Bakunin / The anarchist melodrama Aires de la pampa by Victor Domingo Silva and its articulation of the time according to Mijail Bakunin's libertarian utopia, Revista Izquierdas.cl, número 22, enero 2015, ISSN 0718-5049, Santiago de Chile, pp. 1-19

\title{
El melodrama ácrata Aires de la pampa de Víctor Domingo Silva y su articulación del tiempo según la utopía libertaria de Mijaíl Bakunin
}

\author{
The anarchist melodrama Aires de la pampa by Victor Domingo Silva and its \\ articulation of the time according to Mijail Bakunin's libertarian utopia
}

\section{Pablo Fuentes Retamal**}

\begin{abstract}
Resumen
El presente artículo estudia la pieza teatral Aires de la pampa (1916) de Víctor Domingo Silva para precisar qué aspectos del ideario anarquista aprendidos por el autor, durante la juventud, mantienen vigencia en su práctica escritural posterior. El melodrama Aires de la pampa, en sus pretensiones por representar la agitación social vivida en el puerto de Iquique a comienzos del siglo $\mathrm{XX}$, deja trasver una construcción del tiempo que concuerda con los postulados trazados por Mijaíl Bakunin en su utopía libertaria, vale decir, la preponderancia del Presente en la construcción del porvenir mediante el ejercicio revolucionario.
\end{abstract}

Palabras clave: Víctor Domingo Silva, Aires de la pampa, Anarquismo, Mijaíl Bakunin, tiempo.

\begin{abstract}
The present article examines the play Aires de la pampa (1916) by Victor Domingo Silva with the purpose of specifying what aspects of the anarchist ideology apprehended by the author, during his youth, maintain validy in his subsequent writing practice. The melodrama Aires de la Pampa tries to represent the social unrest experienced in Iquique at the
\end{abstract}

\footnotetext{
* Proyecto Fondecyt Regular $\mathrm{N}^{\circ}$ 1120614, "Cartografía literaria del Norte Grande". Este trabajo fue presentado en las XX Jornadas de Historia de Chile organizadas por la Universidad de Tarapacá en agosto de 2013, Iquique.

${ }^{* *}$ Chileno. Profesor de Estado en Castellano de la Universidad de Santiago de Chile. Magister en Literatura Latinoamericana de la Universidad de Santiago de Chile. Candidato a Doctor en Literatura Latinoamericana de la Universidad de Concepción, Chile p.fuentes.retamal@gmail.com
} 
Pablo Fuentes R., El melodrama ácrata Aires de la pampa de Víctor Domingo Silva y su articulación del tiempo según la utopía libertaria de Mijaíl Bakunin / The anarchist melodrama Aires de la pampa by Victor

Domingo Silva and its articulation of the time according to Mijail Bakunin's libertarian utopia, Revista Izquierdas.cl, número 22, enero 2015, ISSN 0718-5049, Santiago de Chile, pp. 1-19

beginning of the twentieth century, revealing a construction of the time which coincides with the assumptions described by Mijaíl Bakunin in his libertarian utopia. That is to say, the preponderance of the Present for the construction of a Future society by means of the Revolution.

Keywords: Víctor Domingo Silva, Aires de la pampa, Anarchism, Mijaíl Bakunin, time.

\section{Víctor Domingo Silva: poeta, conferencista y activista social en el norte de Chile}

Víctor Domingo Silva Endeiza nace en Tongoy en 1882, por entonces una pequeña caleta de pescadores del norte de Chile. Hijo de comerciante y madre de origen vasco, creció junto a sus quince hermanos ${ }^{1}$ en un hogar cuya biblioteca albergó más de dos mil volúmenes. Por aquellos años, la más completa de toda la zona (Venegas, 30).

Luego de completar la educación secundaria, y tras haber publicado a los catorce años sus primeras creaciones literarias ${ }^{2}$, Víctor Domingo Silva se traslada a la ciudad de Valparaíso. En aquellos entonces el puerto era una ciudad bullente donde "la cuestión social, y las reivindicaciones populares (...) eran parte importante de sus actividades" (Subercaseaux, 10). En tal contexto histórico Silva Endeiza aprehende el credo anarquista, en tanto funda -junto a su hermano Luis, el poeta Zoilo Escobar ${ }^{3}$, e Isaías Gamboa ${ }^{4}$ - el Ateneo de la Juventud (Venegas, 37). Tal institución inauguró una nueva etapa en la cultura porteña al promover la afición por el estudio mediante la creación de la Universidad Popular de Valparaíso ${ }^{5}$ (Iglesias, 54).

En las reuniones del Ateneo de la Juventud, que por lo general se realizaban en algún bar porteño, era habitual que se hablase de:

Ibsen, de Kropotkine o de Tolstoi, de tal modo que los comedorcitos reservados se integraban, y los comensales venían uno por uno a asomar la cabeza para saber quiénes eran esos raros señores que gritaban como en pleno Sahara. (Venegas, 38)

\footnotetext{
${ }^{1}$ Además de Víctor Domingo, en el clan Silva Endeiza destacan sus hermanos: Jorge con Poemas sin fecha (1946); y Hugo, con el Premio Nacional de Periodismo (1955) y la novela Pacha Pulai (1948).

${ }^{2}$ Tales composiciones literarias fueron publicadas en el Folletín de Sucesos por Imprentas y litografías Universo en Valparaíso, 1908.

${ }^{3}$ Zoilo Escobar (1877-1961) fue un poeta anarquista. Únicamente publicó Girasoles de papel (1928). Junto a Víctor Domingo Silva funda la revista Selecta de Valparaíso.

${ }^{4}$ Isaías Gamboa (1872-1904) fue un poeta colombiano. Mientras estuvo en Chile publicó Tres poemas (1902) y la novela La tierra Nativa (1904).

${ }_{5}^{5}$ La Universidad Popular de Valparaíso fue fundada en 1907 por Víctor Domingo Silva, los poetas Horacio Olivos y Carrasco, Zoilo Escobar, y otros intelectuales de la época. Tal institución permitió al pueblo "porteño conseguir esplendidos frutos" (Molina, 80).
} 
Pablo Fuentes R., El melodrama ácrata Aires de la pampa de Víctor Domingo Silva y su articulación del tiempo según la utopía libertaria de Mijaíl Bakunin / The anarchist melodrama Aires de la pampa by Victor

Domingo Silva and its articulation of the time according to Mijail Bakunin's libertarian utopia, Revista Izquierdas.cl, número 22, enero 2015, ISSN 0718-5049, Santiago de Chile, pp. 1-19

En aquellos años el "poeta Silva", tal como sus amigos llamaban a nuestro autor, se siente fuertemente dolido por las matanzas obreras ocurridas en la Huelga de los Estibadores de Valparaíso $^{6}$ (1903) y la Escuela Santa María de Iquique ${ }^{7}$ (1907). A tales nefastos sucesos se añaden las crudas condiciones de vida que enfrentaban las clases más desposeídas de la sociedad chilena de comienzos de siglo:

Analfabetismo, alcoholismo, pésimas condiciones de higiene y salubridad, altas tasas de mortalidad, sobretodo infantil y hacinamiento urbano. Todo ello en un marco en donde se adolecía de políticas sociales. La clase dirigente pensaba, por esos años, que en todos los países del mundo había pobres y que nada se podía hacer. (Venegas, 38)

Entre los jóvenes que frecuentaban el Ateneo fue Víctor Domingo Silva quien sintió con más fuerza la sensibilidad social (Venegas, 40). Tal sentir se aprecia en su extenso poema Desde los conventillos $(1905)^{8}$, donde el hablante lírico interpela la figura divina en búsqueda de respuestas a las injusticias sociales, y además vaticina el nacimiento de un Redentor que surgirá desde el bajo pueblo:

¡Oh, los conventillos! La gran ciudadela

donde la miseria se encierra i batalla...

Hogar del trabajo, de la infamia escuela, rincón desolado donde se desvela

la honradez heroica que el vicio encalla!

(...)

¿Qué noche más triste, más triste, Dios mío!

¿Por qué ya no llegan aquí tus miradas?

Mira que esto es pobre, bien pobre i sombrío...

Aquí reina el hambre, y aquí el viento frío

se entra por las carnes como a puñaladas.

(...)

Desde el conventillo se alzará el profeta

cuya voz sublime llenará el abismo.

$(\ldots)$

\footnotetext{
${ }^{6}$ Los estibadores de Valparaíso declararon la huelga en protesta a las largas jornadas laborales que iban de doce, a catorce, y más horas diarias de trabajo. La represión de tal levantamiento popular arrojó un saldo de "cincuenta muertos, doscientos heridos y un centenar de detenidos" (Jobet, 1973, 54).

${ }^{7}$ Tal masacre fue cometida el 21 de diciembre de 1907 por el General Roberto Silva Renard, quien seguía órdenes del Ministro del Interior Sotomayor Gaete. Se han presentado fuertes discrepancias historiográficas respecto del número de fallecidos en Santa María, al respecto el historiador Iván Ljubetic señala: "la cifra de 2.000 muertos" (8). A su vez, Julio César Jobet en Ensayo crítico del desarrollo económico-social de Chile (1951), avalándose en los comentarios de su padre, quien al momento de la matanza desempeñaba labores de suboficial en el regimiento Carampangue, indica: "las bajas alcanzaron a 2.000, pues a él (Armando Jobet Angevin) le correspondió el primer turno de entrega de cadáveres contando 900" (123).

${ }^{8}$ Tal composición lírica fue publicada en el poemario Hacia allá... poemas orijinales (1905).
} 
Pablo Fuentes R., El melodrama ácrata Aires de la pampa de Víctor Domingo Silva y su articulación del tiempo según la utopía libertaria de Mijaíl Bakunin / The anarchist melodrama Aires de la pampa by Victor

Domingo Silva and its articulation of the time according to Mijail Bakunin's libertarian utopia, Revista Izquierdas.cl, número 22, enero 2015, ISSN 0718-5049, Santiago de Chile, pp. 1-19

¡I una entraña virjen dará un nuevo Cristo

i tendrán los hombres un nuevo Evanjelio! (148)

No conforme con la vida porteña, el poeta Silva se traslada hasta las localidades más septentrionales del país. Emprende dicho viaje con dos propósitos: difundir la vida cultural en las provincias más alejadas de la capital, y conocer personalmente las realidades vividas en tales parajes. Para entonces, Víctor Domingo Silva ha acuñado su premisa de escritura: "conocer en profundidad los espacios, para luego, escribir y describirlos con prolijidad" (Venegas, 108). Respecto de su pretensión escritural nos habla el propio poeta en una entrevista otorgada a El Mercurio de Antofagasta:

Presenta la vida de estos pueblos (del norte de Chile) tantos aspectos interesantes y hasta originales (...) se ofrece a la visión del observador tanto problema de vital importancia para el porvenir nacional, que un escritor que estima su profesión no puede menos que sentirse atraído a su estudio. Todavía no se ha escrito el libro que desapasionadamente, y con experiencia y conocimiento de la patria describa en conjunto y detalladamente vida tan especial, tan opuesta por concepto a la que se hace en el resto de las provincias. (Venegas, 108)

Víctor Domingo Silva inicia su periplo cultural en La Serena, más tarde continúa en Copiapó, y Antofagasta. Tras dos meses de recorrido finaliza su trayecto en el puerto de Iquique. En esta ciudad su labor cultural y social rinde sus mayores frutos, pues ofrece dos conferencias ${ }^{9}$, visita cooperativas socialistas, y además estrena su obra Como la ráfaga (1913). Un antecedente fundamental para comprender el contexto en que se inscribe la visita de Víctor Domingo Silva a Iquique fue la presencia, con tan sólo unas semanas de antelación, de Belén de Sárraga: "librepensadora, anarquista y feminista" (Gumucio, 23).

La pensadora española realizó dos visitas a nuestro país. En una primera ocasión ofreció nueve conferencias cuyo tópico fue el Anticlericalismo. La primera charla, titulada Trayectorias humanas (1913), traza los lineamientos que más tarde siguieron sus presentaciones posteriores:

Aparte de esa patria chica, de ese concepto de la patria que todos poseemos (...) existe otra Patria Grande, inmensa, que no tiene frontera, tan grande señores, tan inmensa y tan infinita como la idea que ella cobija. Inmensa, porque recoge a todas las patrias; infinita porque recoge todas las grandes ideas (...) en esa Patria, señores, que es la Patria de la Ciencia, que es la Patria del Progreso, que es la Patria del Pensamiento Libre, en esa Patria, señores, (...) los corazones se unen con el entusiasmo del amor a

\footnotetext{
${ }^{9}$ La primera de aquellas conferencias titulada El presente y el porvenir de las provincias del norte denuncia las inequidades sociales vividas en la época. La segunda conferencia denominada El arte y la humanidad, o los poetas del dolor presenta un alegato en favor de la poseía romántica destacando las labores de los poetas: Eusebio Lillo, José Antonio Soffía, Guillermo Blest Gana, Luis Rodríguez Velasco, Pablo Garriga, Eduardo de la Barra y Guillermo Matta.
} 
Pablo Fuentes R., El melodrama ácrata Aires de la pampa de Víctor Domingo Silva y su articulación del tiempo según la utopía libertaria de Mijaíl Bakunin / The anarchist melodrama Aires de la pampa by Victor Domingo Silva and its articulation of the time according to Mijail Bakunin's libertarian utopia, Revista Izquierdas.cl, número 22, enero 2015, ISSN 0718-5049, Santiago de Chile, pp. 1-19

las grandes ideas y sentimientos fundamentales, en el amor a los pueblos y en el amor de las Libertades populares. (de Sárraga, 8-9)

El escritor González Vera tuvo la fortuna de asistir a las presentaciones de Sárraga, y presenciar la efervescencia que suscitaba la conferencista española sobre el público chileno. En su texto autobiográfico Cuando era muchacho (1951) el autor comenta que a tales conferencias asistían en masa "caballeros de negro, proletarios y obreros que fervorosos proclamaban: "¡Viva el libre pensamiento! ¡Viva el comunismo anárquico! ¡Viva la revolución social!” (141).

En su segunda visita a nuestro país, Belén de Sárraga se traslada hasta el puerto de Iquique. Lo hace en medio de grandes recibimientos, discursos y fiestas "organizados por el Partido Obrero Socialista, el Centro de Estudios Sociales "La Redención", el Centro Anticlericalista Belén de Sárraga, La Juventud Socialista, el Centro “Arte y Revolución” y la Estudiantina "Germinal"” (Vitale, 2000, 113). A tales organizaciones populares Rafael Gumucio añade "la lealtad y el entusiasmo de los anarquistas" (36).

Para el pueblo iquiqueño la visita de Víctor Domingo Silva significó la continuación de lo realizado tiempo atrás por Belén de Sárraga ${ }^{10}$, por ello, el periódico La Patria invitó a participar activamente en las presentaciones del poeta Silva que, como las de Belén de Sárraga, dejarían huellas profundas en su instrucción (Venegas, 110).

Debido a lo anterior, fue habitual que durante las actividades realizadas por Víctor Domingo Silva se oyesen al unísono proclamas en favor suyo y de la activista española. Este hecho quedó registrado durante la visita a la oficina salitrera La Alianza, donde los asistentes prorrumpieron "con vivas a Víctor Domingo Silva y a Belén de Sárraga" (Venegas, 125). La misma situación se repite el 29 de mayo de 1913 en las calles iquiqueñas durante el desfile organizado por las Juventudes Radicales en honor al poeta Silva:

Los manifestantes, al grito de "viva el librepensamiento", "viva Belén de Sárraga, "viva el Liberalismo", siguieron por las calles Bulnes hasta llegar a Vivar, donde siguió por Riquelme, hasta tomar nuevamente Baquedano, para llegar a la Plaza Prat. Durante el trayecto el pueblo entonaba la canción Yungay, variando el coro por la siguiente oportuna parodia, cantemos las glorias del libre pensar, que obtuvo el triunfo en Tarapacá ${ }^{11}$. (Venegas, p.123)

\footnotetext{
${ }^{10}$ Belén de Sárraga presentó en el Teatro Municipal de Iquique su conferencia titulada El peligro de América. En ésta analizó "el error de los pueblos de América al confiar la educación en manos de los clericales porque éstos terminan, moral e intelectualmente con todo progreso de libertad y de justicia" (Vitale, 2000, 116). La segunda conferencia se denominó La guerra y la religión. Finalmente, la tercera conferencia se tituló La Iglesia y la política, en ella la activista ácrata subraya que tal institución "unida a los reyes se hizo poderosa, al extremo que el papado pudo arrastrar a los fieles a revoluciones contra el propio poder del Estado" (Vitale, 116).

${ }^{11}$ Tales versos corresponden al Himno de la victoria de Yungay compuesto en 1839 por José Zapiola Cortés. Los versos parodiados corresponden al coro de dicha canción que originalmente propone: "Cantemos la gloria / del triunfo marcial / que el pueblo chileno / obtuvo en Yungay".
} 
Pablo Fuentes R., El melodrama ácrata Aires de la pampa de Víctor Domingo Silva y su articulación del tiempo según la utopía libertaria de Mijaíl Bakunin / The anarchist melodrama Aires de la pampa by Victor

Domingo Silva and its articulation of the time according to Mijail Bakunin's libertarian utopia, Revista Izquierdas.cl, número 22, enero 2015, ISSN 0718-5049, Santiago de Chile, pp. 1-19

El contacto con la gente del norte, el conocimiento de sus problemas, necesidades e intereses fueron desencadenantes que dieron lugar a la escritura de Aires de la pampa (1916). El montaje de esta pieza teatral se realizó en el Teatro Municipal de Iquique bajo la dirección de Bernardo Jambrina ${ }^{12}$. En los meses siguientes el melodrama fue reestrenado en Santiago junto a la comedia Los muertos (1905) de Florencio Sánchez, quien por aquellos entonces "no sólo era la figura más importante del anarquismo uruguayo [sino que además] era el más alto exponente del teatro rioplatense" (Capelletti, LXVII).

Si bien Aires de la pampa se concibe, escribe y estrena en un contexto ácrata -tanto por la significación libertaria aprehendida por el poeta Silva en la juventud, la visita de Belén de Sárraga a Iquique, y el reestreno del melodrama junto al trabajo de Florencio Sánchez- para 1916 Víctor Domingo Silva ha asumido una activa militancia en el Partido Radical $^{13}$.

Erróneamente podríamos pensar que el distanciamiento del anarquismo en pos del radicalismo se traduce en quiebres o rupturas en la práctica escritural de Víctor Domingo Silva. Recordemos que para comienzos del siglo XX las diferencias ideológicas entre los conglomerados de izquierdas no eran tan decisivas y categorías como lo son actualmente. En razón de estas fronteras ideológicas permeables, el historiador Sergio Grez señala que "al interior del Partido Democrático existían tendencias radicales influidas por el anarquismo y el socialismo. Por otra parte, las fronteras entre el socialismo marxista y el socialismo libertario eran más bien difusas" (38). De la misma opinión es Julio Pinto en Desgarros y utopías en la pampa salitrera... (2007) al sostener que no era extraño que anarquistas de la región "apareciesen dentro de corto lapso, identificados con mancomunados o demócratas" (53).

La historiografía se ha preocupado de estudiar esta ambigüedad ideológica entre los conglomerados de izquierdas de comienzos del siglo pasado; por ejemplo, entre quienes transitaron del anarquismo a otras militancia de izquierda, se pueden apuntar: Óscar Schnake (dirigente socialista), Juan Chacón ${ }^{14}$ (dirigente comunista), César Godoy Urrutia (dirigente socialista y posteriormente comunista), entro otros. Lamentablemente, desde una mirada literaria, no existen trabajos que aborden y estudien esta problemática.

Considerando este difuso panorama político, que en el caso de Víctor Domingo Silva transita desde el anarquismo al radicalismo, surge esta propuesta de trabajo que pretende indagar y precisar qué sedimentos ácratas subyacen en la escritura del melodrama Aires de la pampa.

\footnotetext{
${ }^{12}$ Actor español nacido en La Coruña, muy afamado en aquella época. A partir de 1914 realizó gira por varios países latinoamericanos, entre los que cuentan Colombia, Chile, Venezuela, Nicaragua, y Perú.

${ }^{13}$ Siendo fiel a la tradición familiar Víctor Domingo Silva adhiere al partido Radical, al igual que su padre y hermanos mayores.

${ }^{14}$ José Miguel Varas se preocupa de relatarnos el transito del dirigente Juan Chacón desde el anarquismo al comunismo. Respecto de la militancia ácrata de Chacón su biografía novelada sugiere: "la pelea revolucionaría la entendí durante mucho tiempo, tal vez por influencia anarquista, como una tarea individual (...) un libro leí de todas maneras, que me causó impresión. Fue "La conquista del Pan" de Kropotkin, la Biblia de los anarquistas. Me gustó la forma como enfocaba hechos sociales" (37). Más tarde, respecto de la militancia comunista de Chacón el mismo texto señala: "cuando fui diputado, empecé a leer más. Me atreví con las obras escogidas de Lenin (...) de Marx leí "Economía y política" y algunas partes de "El Capital"; "El Manifiesto Comunista"; y "El Brumario 18" (...) claro, un diputado comunista no lleva una vida descansada. (116).
} 
Pablo Fuentes R., El melodrama ácrata Aires de la pampa de Víctor Domingo Silva y su articulación del tiempo según la utopía libertaria de Mijaíl Bakunin / The anarchist melodrama Aires de la pampa by Victor

Domingo Silva and its articulation of the time according to Mijail Bakunin's libertarian utopia, Revista Izquierdas.cl, número 22, enero 2015, ISSN 0718-5049, Santiago de Chile, pp. 1-19

La conjetura de trabajo propuesta sugiere que la articulación del tiempo que se propone en el melodrama del poeta Silva se ajusta a los postulados trazados por Mijaíl Bakunin en su utopía libertaria, vale decir, la preponderancia del "Presente" en la construcción del porvenir mediante la Revolución.

A primera vista pareciese que Víctor Domingo Silva y Mijaíl Bakunin son figuras lejanas cuya relación es forzada y poco natural, no obstante, ambos pensadores convergen al considerar junto a Luis Vitale que el movimiento anarquista en Chile se configuró "en la década de 1880-1890 con la llegada de obreros europeos, de inspiración bakunista, que pronto contactaron con Manuel Chinchilla ${ }^{15}$, un español residente en Iquique" $(1992,201)$.

Hemos decidido privilegiar el estudio de este aspecto puntual de Aires de la pampa para atestiguar la vigencia de la militancia ácrata aprehendida por el poeta Silva, durante la juventud, con su programa escritural posterior. Esta pauta de trabajo es doblemente provechosa, pues no sólo discute la vigencia del acervo cultural ácrata en Aires de la pampa, sino que además tales parámetros de reflexión podrían extenderse a toda la escritura posterior de Víctor Domingo Silva.

Antes de introducirnos en Aires de la pampa es necesario repasar las implicancias de la utopía libertaria bakunista en lo referente a la articulación del tiempo histórico.

\section{La utopía libertaria de Mijaíl Bakunin y su articulación del tiempo histórico}

Definir "Utopía" es una tarea compleja que se dificulta al aislar un núcleo capaz de definirla, pues las "Utopías (en plural) no expresan fácilmente una significación central de las Utopía (en singular)" (Ricoeur, 290). En razón de estas complejidades metodológicas, es prudente abordar cada proyecto utópico desde sus particularidades.

No obstante las dificultades para precisar una definición capaz de aprehender las diversas aristas que definen "utopía", siguiendo las recomendaciones de Paul Ricoeur, el trabajo Ideología y utopía: Introducción a la sociología del conocimiento (1941) de Karl Mannheim "proporciona un buen instrumento sociológico para tratar las dificultades mencionadas" (291). De acuerdo al sociólogo húngaro, son utópicas "aquellas orientaciones que trascienden la realidad y que, al informar de la conducta humana, tienden a destruir, parcial o totalmente, el orden de las cosas predominantes en aquel momento" (267-8). En esta categorización se inscriben cuatro proyectos en la época moderna: "la utopía quiliástica orgiástica anabaptista" (línea que posteriormente sigue la utopía libertaria de Bakunin), "la utopía humanitaria liberal", "la utopía conservadora" y "la utopía socialista-comunista". (Mannheim, 296).

De las diversas aristas que constituyen un sistema utópico es indispensable estudiar el modo que cada cual otorga al trascurso del tiempo, ya que este aspecto permite trasver el imaginario sobre el que se construye una determinada utopía:

La forma en que un grupo concibe el tiempo constituye uno de los exponentes más claros del tipo de utopía, en consonancia con el

\footnotetext{
${ }^{15}$ Manuel Chinchilla fue un ácrata de origen español que en sociedad con Carlos Jorquera funda en 1892 el primer Centro de Estudios Sociales en Chile. De la misma manera, publica en Valparaíso el primer periódico ácrata de circulación nacional: El Oprimido.
} 
Pablo Fuentes R., El melodrama ácrata Aires de la pampa de Víctor Domingo Silva y su articulación del tiempo según la utopía libertaria de Mijaíl Bakunin / The anarchist melodrama Aires de la pampa by Victor

Domingo Silva and its articulation of the time according to Mijail Bakunin's libertarian utopia, Revista Izquierdas.cl, número 22, enero 2015, ISSN 0718-5049, Santiago de Chile, pp. 1-19

cual está organizada su conciencia. El tiempo se experimenta aquí como una serie de puntos estratégicos. (Mannheim, 326-7)

Antes de enfocarnos en el imaginario utópico bakunista es necesario referirnos a los parámetros trazados dos siglos antes por Thomas Müntzer en la utopía quiliástica orgiástica anabaptista ${ }^{16}$. Recordemos que Karl Mannheim sostiene que el movimiento utópico alemán "debe ser considerado un paso en la dirección de los movimientos revolucionarios modernos" (290). Paul Ricoeur coincide con esta observación, reforzando que es posible trazar una línea que va desde Müntzer hasta Bakunin, pues en ambas utopías "se desencadenan las mismas energías por obra del puente tendido entre un ideal y una demanda terrenal que viene desde abajo" (296).

La utopía anabaptista surge en respuesta a la Dieta de Espira (1529) que promulga la existencia de un Dios único y la trascendencia de las Sagradas Escrituras ${ }^{17}$ (Castelar, 561). Tal decreto provocó que los anabaptistas fuesen perseguidos y censurados por católicos y protestantes, ya que para entonces las diferencias teológicas suscitadas entre ambos bandos eran irreconciliables. Mientras los sectores ortodoxos concebían a Dios "un ser omnipresente en el universo" (Castelar, 561), los segmentos fieles a Müntzer entendían la Divinidad vinculada a condiciones materiales de existencia, por lo que promulgaban el "advenimiento de un reinado milenario sobre la tierra" (Mannheim, 289).

La doctrina anabaptista se apuntó con fuerza entre los sectores desposeídos de la sociedad europea del siglo XVI. En razón de ello, Jean Delumeau sostiene en Historia del Milenarismo en occidente (2001) que el movimiento liderado por Thomas Müntzer "fue una de las explosiones más fuertes (...) [provocando que] los anabaptistas más exaltados creyesen que Cristo se haría presente para construir una "Nueva Jerusalén"" (7). Aquellos sectores que acogieron el mensaje de Müntzer propusieron un vuelco sustancial en el tratamiento del tiempo, ya que, a diferencia de otras doctrinas religiosas que vinculaban a Dios con un tiempo ultraterrenal ${ }^{18}$, los anabaptistas comprendieron que sus demandas podrían alcanzarse "aquí y ahora".

La valoración que Thomas Müntzer otorga al Presente quedó registrada en sus sermones y predicas. Citamos un fragmento pertinente: "por esta razón, todos los profetas deberían hablar de esta forma: "Así dice el Señor", y no "Así decía el Señor", como si hubiese ocurrido en el pasado en lugar de en el presente" (Mannheim, 294). Müntzer vuelve a subrayar aquella disposición temporal al señalar: "debe saber (el anabaptista) que Dios está dentro de él y no debería pensar sobre Él como si estuviera a millas de distancia" (Mannheim, 294).

\footnotetext{
${ }^{16}$ En Mannheim véase pág. 289 y ss.

${ }^{17}$ El siguiente pasaje de la Dieta de Espira facilita la comprensión de los aspectos fundamentales de tal decreto teológico: "Lo único fijo en el Universo es la palabra de Dios; y el único documento, en que la palabra de Dios se encuentra, es la Divina Escritura (...) Dios [es] nuestro único Creador, Conservador, Redentor, y Salvador, el cual será un día nuestro juez, así como delante de todos los hombres y de todas las criaturas, que no consentiremos ni nos adheriremos de ningún modo por nosotros, ni por los nuestros, al decreto propuesto en todo aquello contrario á Dios, á su santa palabra, á nuestra honrada conciencia, á la salud de las almas, y al último decreto de Espira" (Castelar, 561-2).

${ }^{18}$ Para los sectores tradicionalistas el tiempo divino se ajusta al Illud tempus, es decir, en palabras de Gilbert Durand, un espacio temporal en que "pasado y porvenir no depende el uno del otro, y en donde los acontecimientos son capaces de revisión, de relectura, de letanía y rituales repetitivos" (100).
} 
Pablo Fuentes R., El melodrama ácrata Aires de la pampa de Víctor Domingo Silva y su articulación del tiempo según la utopía libertaria de Mijaíl Bakunin / The anarchist melodrama Aires de la pampa by Victor

Domingo Silva and its articulation of the time according to Mijail Bakunin's libertarian utopia, Revista Izquierdas.cl, número 22, enero 2015, ISSN 0718-5049, Santiago de Chile, pp. 1-19

Para el anabaptista el tiempo Presente es la instancia propicia para acudir tras la utopía del Porvenir, la que únicamente se alcanza mediante el ejercicio de la Revolución:

El quiliaísmo ve la Revolución como algo valioso por sí mismo, no como un medio inevitable para conseguir un fin establecido racionalmente, sino como el único principio creador del presente inmediato, como la realización deseada de sus aspiraciones en este mundo. (Mannheim, 286)

La importancia y trascendencia de la utopía anabaptista se justifica al considerar, junto con Paul Ricoeur, que el proyecto liderado por Müntzer traza los parámetros temporales sobre los que se construyen las utopías modernas. Por ello, Karl Mannheim no se cansa al enfatizar que la utopía anabaptista dibuja una línea directa sobre el proyecto de Bakunin, pues "el anarquismo, en su versión bakunista, llega a estar muy cerca (...) de ser la continuación de la concepción quiliástica en el mundo moderno" (296-7).

Mijaíl Bakunin concretiza las convergencias entre su proyecto utópico y el de Müntzer en Segunda charla: sobre la acción durante la Revolución y la guerra civil (1870) al estimar el Presente un tiempo propicio en la prosecución de la redención proletaria: "Ahora tenemos que embarcarnos juntos por el océano revolucionario, y en adelante debemos propagar nuestros principios no ya con palabras, sino con hechos" (Mintz, 34-5).

El deíctico temporal "ahora" que inicia el fragmento citado establece la disposición temporal desde la que Bakunin construye su proyecto utópico. La misma idea se vuelve a repetir en Carta de despedida a los revolucionarios (1873), donde el ácrata sostiene: "los tiempos ya no son para las ideas, sino para los hechos y los actos. Ante todo es preciso hoy por hoy organizar las fuerzas del proletariado" (Bakunin, 2008).

Al igual que las predicas de Müntzer, los discursos bakunistas también evidencian la predilección por el Presente:

No creáis que estamos al final de la Revolución, estamos en su comienzo. La Revolución estará ya a la orden del día para muchas decenas de años (...) preparémonos dignamente para esta lucha que debe salvar a todos los pueblos y emancipar finalmente a la humanidad. (Velasco, 189)

El proyecto utópico de Bakunin se erige desde el Presente con miras al Porvenir, pretendiendo que el hombre se constituya en un fin en sí mismo al eliminar todos los obstáculos y alienaciones ${ }^{19}$ que se le han impuesto (Velasco, 187). El pensador ácrata es consciente que la destrucción del principio de autoridad creará las condiciones necesarias para la redención de las clases proletarias, por ello la primera tarea revolucionaría será:

\footnotetext{
${ }^{19}$ Para Bakunin aquellos obstáculos que impiden el desarrollo pleno del hombre son la Religión y el Estado. El ácrata reprueba ésta primera institución, pues "condena (al hombre) al absurdo, le dirige por una vía falsa y le hace buscar lo divino en vez de buscar lo humano" (Bakunin, 89). En cuanto al Estado lo crítica por ser "el violador legal de voluntades, el permanente negador de la libertad (...) incapaz de dar felicidad y libertad a sus súbditos, aunque los llame "ciudadanos"” (91-2).
} 
Pablo Fuentes R., El melodrama ácrata Aires de la pampa de Víctor Domingo Silva y su articulación del tiempo según la utopía libertaria de Mijaíl Bakunin / The anarchist melodrama Aires de la pampa by Victor

Domingo Silva and its articulation of the time according to Mijail Bakunin's libertarian utopia, Revista Izquierdas.cl, número 22, enero 2015, ISSN 0718-5049, Santiago de Chile, pp. 1-19

\begin{abstract}
Abatid y echad por tierra a todos los que os oprimen. Después, una vez seguros de la victoria y de haber destruido lo que hacía fuertes a vuestros enemigos, ceded a un movimiento de humanidad y levantad a esos pobres abatidos $\mathrm{y},(\ldots)$ reconocedle como vuestros hermanos e invitadle a vivir y a trabajar con vosotros, sobre el inquebrantable suelo de la igualdad. (Velasco, 196)
\end{abstract}

La consecución de la Revolución dará lugar a una tercera etapa en la utopía bakunista que posibilitará "la Libertad de las masas (...) en un porvenir próximo en esa jornada del mañana que debemos crear nosotros mismos, por la potencia de nuestro pensamiento, de nuestra voluntad, pero también por la de nuestros brazos" (Fuentes, 12).

Una vez aclarados los parámetros temporales desde los que se construye la utopía bakunista, procedemos a analizar la influencia que ejerció dicho proyecto utópico en la escritura del melodrama Aires de la pampa de Víctor Domingo Silva.

\title{
El melodrama Aires de la pampa y su articulación del tiempo según la utopía libertaria de Mijaíl Bakunin
}

El lunes 16 de abril de 1917 El Mercurio de Santiago publica una extensa nota informando del reestreno de Aires de la pampa en la capital. Respecto del argumento del melodrama se señala:

En una oficina salitrera un gringo, el administrador, da a su mujer una vida triste que ofrece a diario escenas de hogar propias de un marido autoritario entregado por entero al whisky. Esa desventurada mujer se siente comprendida por el oficial de carabineros acantonado allí, quien, en su loco frenesí, concibe la idea de un rapto, de irse con ella pampa adentro, donde nadie puede alcanzarlos.

(...)

La mujer después de una escena violenta de celos con su marido se decide a abandonar el hogar, llega el raptor... todo está listo; pero un chiquitín, su hijito que duerme, despierta y la llama. Ante aquel "mamacita" siente todo el amor de su madre, triunfando sobre todos los amores, vuelve a él y le dice al raptor... déjame... déjame para siempre... (Venegas, 209-10)

Como vemos, la pieza teatral estudiada sugiere una pugna entre dos circuitos bien definidos: uno ligado al poder, en donde únicamente se inscribe Jaime, el dueño de la salitrera; y otro conformado por subalternos, es decir, Chabela, su esposa; Lalo, el primogénito; Mariano, el policía que comparte un romance secreto con la mujer; la servidumbre y trabajadores mineros.

La tensión dialéctica propuesta en Aire de la pampa se ajusta a lo descrito por Sergio Pereira Poza para la dramaturgia anarquista. En ésta se sugiere la presencia de un circuito dominante que pretende imponer sus aparatos de legitimación a un sector subalterno; éstos, por su parte, pugnan por establecer "una conciencia crítica de la realidad 
Pablo Fuentes R., El melodrama ácrata Aires de la pampa de Víctor Domingo Silva y su articulación del tiempo según la utopía libertaria de Mijaíl Bakunin / The anarchist melodrama Aires de la pampa by Victor

Domingo Silva and its articulation of the time according to Mijail Bakunin's libertarian utopia, Revista Izquierdas.cl, número 22, enero 2015, ISSN 0718-5049, Santiago de Chile, pp. 1-19

en función de los olvidados principios de la equidad social, la solidaridad, la tolerancia cultural y la libertad del hombre" $(2009,150)$.

Jaime, el dueño de la salitrera, valida su posición de poder mediante humillaciones y tratos degradantes para con sus subalternos. Respecto de la relación que mantiene con su esposa Chabela, apuntamos lo siguiente:

Jaime: Chabela, sirve.

Chabela: si acabamos de beber...

Jaime: sirve (Chabela sirve resignada, en Mariano se observa un gesto de fastidio. Beben).

Jaime: este whisky está detestable.

Mariano: Yo lo encuentro delicioso amigo Jaime.

Chabela: lo preparé yo misma

Jaime: no se puede beber (...) ¡Estas mujeres no sirven para nada! Lo felicito a usted, teniente.

Mariano: ¿Y por qué, mi amigo?

Jaime: Porque usted es soltero. Si no quiere morirse de desesperación, no se case usted nunca. (220)

Podemos añadir un segundo pasaje del melodrama Aires de la pampa que evidencia las vejaciones que Jaime propina a su mujer:

Chabela: Jaime, ¿te alisto la tenida de smoking?

Jaime: Eso no se pregunta.

Chabela: es que como otras veces te niegas a cambiarte de ropa...

Jaime: Bueno... ¡basta! Ya vuelvo.

(...)

Chabela: Jaime, la ropa está lista. ¿Quieres vestirte?

Jaime: No, te he dicho que no. ¡Hasta cuándo!

Chabela: Me habías dicho que sí, Jaime. Te lo he preguntado expresamente.

Jaime: ya te he dicho que no. No seas majadera. (228)

Estimamos que el dramaturgo no ha escogido azarosamente las desavenencias entre Jaime y Chabela. Tal elección cobra sentido al considerar Carta a Pablo ${ }^{20}$ (1845) de Bakunin, pues en aquel texto el ácrata subraya la importancia del Amor en la doctrina libertaria:

Amar es querer la libertad, la completa independencia de otro; el primer acto del verdadero amor es la emancipación completa del objeto que se ama; no se puede amar verdaderamente más que a un ser perfectamente libre, independiente, no sólo de todos los demás, sino aun y sobre todo de aquel de quien se es amado y a quien se ama.

\footnotetext{
${ }^{20}$ Tal carta fue escrita el 29 de marzo de 1845 en París. En aquella epístola Mijaíl Bakunin le comenta a su hermano Pablo que el Amor ha de ser capaz de superar la visión autoritaria, en el sentido que uno/a y otro/a son propiedad recíproca, para dar lugar a una relación sustentada en la Libertad y el desarrollo íntegro del individuo.
} 
Pablo Fuentes R., El melodrama ácrata Aires de la pampa de Víctor Domingo Silva y su articulación del tiempo según la utopía libertaria de Mijaíl Bakunin / The anarchist melodrama Aires de la pampa by Victor Domingo Silva and its articulation of the time according to Mijail Bakunin's libertarian utopia, Revista Izquierdas.cl, número 22, enero 2015, ISSN 0718-5049, Santiago de Chile, pp. 1-19

He ahí mi profesión de fe política, social y religiosa, he ahí el sentido íntimo, no sólo de mis actos y de mis tendencias políticas, sino también, en tanto que puedo, el de mi existencia particular e individual. (Baigorria, 25-6)

Tal como se adelantó, Jaime, el dueño de la salitrera, se refiere a su hijo, mayordomo, servidumbre, y trabajadores mineros mediante insultos degradantes. El empresario minero utiliza el despectivo "animales" para referirse a quienes estima subalternos. Respecto de las ofensas que el empresario salitrero adjudica a su hijo, señalamos:

Jaime: ¿Qué hacías?

Chabela: El niño quería que le aseasen y tuve que ir yo misma.

Jaime: Lo habrás castigado.

Chabela: ¿Y para qué?

Jaime: Para que no resulte un animal. (228) [Énfasis nuestro]

En cuanto a las vejaciones propinadas al mayordomo, indicamos:

Chabela: prepare usted otro whisky-sower.

Mayordomo: ¿Cargadito?

Jaime: Ya sabes como a mí me gustan.

(...)

Jaime: Ese hombre es también un animal. Además es un ladrón, se lo roba todo. (220) [Énfasis nuestro]

Cuando Jaime se entera que uno de sus trabajadores mineros ha sufrido un accidente laboral, responde de la siguiente manera:

Jaime: ¿Qué hay algo?

Sinecio: No sé. Creo que hay algo en los cartuchos...

Jaime: Cuando menos, es un imbécil que se ha caído dentro (de la barrenadora). Es inútil decirles que pongan cuidado...

Chabela: Más fácil sería ponerle rejas...

Jaime: ¿Qué sabes tú? Ese jefe de máquinas es también un animal. No hace más que disparates. (221) [Énfasis nuestro]

A primera vista pareciese que las referencias a la supuesta "animalidad" de Lalo, el mayordomo y trabajadores mineros no son más que insultos degradantes; sin embargo, para Bakunin, tales referencias adquieren un matiz bastante peyorativo, pues para el ácrata ruso la evolución histórica del hombre transita por una vía perpetua de ascenso que va "desde lo simple a lo complejo, de lo inferior a lo superior, de abajo a arriba" $(2010,85)$. En búsqueda de tal constante evolución, el individuo debe ser capaz de abandonar su "animalidad" para caminar en prosecución del desarrollo pleno que otorga la Libertad:

El hombre originariamente es un animal salvaje, un pariente del gorila. Pero una vez fuera de la noche profunda del instinto animal, 
Pablo Fuentes R., El melodrama ácrata Aires de la pampa de Víctor Domingo Silva y su articulación del tiempo según la utopía libertaria de Mijaíl Bakunin / The anarchist melodrama Aires de la pampa by Victor Domingo Silva and its articulation of the time according to Mijail Bakunin's libertarian utopia, Revista Izquierdas.cl, número 22, enero 2015, ISSN 0718-5049, Santiago de Chile, pp. 1-19

alcanza la luz del espíritu. Así nos explica, del modo más natural del mundo, sus primeros extravíos y nos consuela, de alguna manera, de sus errores presentes. Deja atrás la esclavitud animal, camina por el campo de la esclavitud divina que ocupa el punto intermedio entre la existencia animal y la humana, y comienza a ver de frente la libertad. (Bakunin, 86)

Este crudo panorama se tensa, aún más, al considerar la predilección de Jaime por el alcohol. Tal inclinación se evidencia durante toda la acción dramática, ya que siempre se muestra al empresario salitrero con una copa de licor en la mano:

Jaime: ¿Qué? ¿Qué quieres?

Chabela: No bebas tanto; recuerda que tenemos visitas.

Jaime: ¡Pero a ti qué te importa! Bebo porque se me antoja. Bebo porque esta vida es estúpida, horrible, y tú no sabes o no quieres hacérmela agradable... Me emborracho por no pegarme un tiro... (229)

Consideramos que la debilidad de Jaime por el licor no es un detalle superfluo en la acción dramática de Aires de la pampa, sino que por el contrario su incorporación adquiere sentido al considerar que para el pensamiento bakunista la bebida es un arma detonada por la clase burguesa para adormecer al proletariado, y así retardar la redención social. Por ello, Bakunin insiste que el pueblo tiene tres caminos para escapar de su misérrima suerte: "dos imaginarios y uno real. Los dos primeros son la taberna y la iglesia. El tercero es la revolución social" $(2010,101)$. Este tercer camino es el que escogen los agonistas de Aires de la pampa para ir tras la libertad:

Chabela: Mariano, es necesario que esto concluya. Esto no puede seguir así.

Mariano: Sí es lo que te estoy diciendo todos los días, cada vez que puedo... Esto debe terminar; me cansa el disimulo... me fatiga la farsa iya no puedo más! (...)

Mariano: Tú no puedes imaginarte lo que sufro, la angustia y la rabia con que me muerdo cuando te veo maltratada por tu marido. Hace un momento, créelo, estuve a punto de estallar, de echarlo todo a perder.

Chabela: ¡Oh, no! hay que resistir, hacerse fuertes.

Mariano: ¡Resistir, disimular contenerse!... ¿y hasta cuándo? (222-3)

La pregunta formulada por Mariano, “¿hasta cuándo?”, sólo se resuelve al considerar el modo en que los agonistas conciben el transcurso del tiempo.

Mariano: ¡Esto es terrible! ¿Ves? No queda más que hacer lo que te he dicho tantas veces.

Chabela: ¡Huir! ¿Huir contigo? ¡Una locura! ¡Un crimen!

Mariano: Crimen es el que estás cometiendo.

(...)

Tú reivindicas tu derecho a la felicidad, al amor. Crimen es lo que estás cometiendo al sacrificarte como lo haces, en esta soledad, en este desierto, en la compañía de un salvaje... (223-4). 
Pablo Fuentes R., El melodrama ácrata Aires de la pampa de Víctor Domingo Silva y su articulación del tiempo según la utopía libertaria de Mijaíl Bakunin / The anarchist melodrama Aires de la pampa by Victor

Domingo Silva and its articulation of the time according to Mijail Bakunin's libertarian utopia, Revista Izquierdas.cl, número 22, enero 2015, ISSN 0718-5049, Santiago de Chile, pp. 1-19

Con cierta timidez Chabela acepta la invitación de Mariano, plasmando su consentimiento en el lenguaje corporal:

Mariano: (...) Mi pobre chiquilla... ¡A ver si crías valor y te decides! (Le tiende las dos manos, que ella estrecha con efusión, él quiere atraerla a si como para darle un beso; pero ella, temerosa de ser sorprendida, le rechaza dulcemente). (p.225).

En escenas posteriores el espíritu revolucionario de Chabela se fortalece, y no hay titubeos al indicar el camino revolucionario que habrá de emprender:

Mariano: (al oído de Chabela) ¡Alma mía, por Dios, decídete! ¿Sí? ¿Sí?... (Tendiéndole una mano).

Chabela: (estrechándosela después de un gran esfuerzo) ¡Sí! (229)

El discurso de Mariano deja trasver que la redención social se concibe desde el Presente, por ello, sus monólogos precisan una serie de referencias que aluden tal disposición temporal:

Mariano: Escúchame, haz lo que te digo. Di que sí, pronuncia esa palabra, y de aquí a una hora estaremos lejos de la oficina. No me preguntes a dónde iremos, no importa dónde sea... Di que sí... alma mía. Decídete, decídete alguna vez... (224) [Énfasis nuestro]

Los monólogos juegan un papel fundamental en el teatro ácrata. Este recurso dramático refuerza el carácter pedagógico de la escritura anarquista, en palabras de Pereira Poza, las formas monologadas son un recurso apelativo para implicar ideológicamente al destinatario al reforzar el contenido didáctico del discurso $(2005,154)$.

Siguiendo los postulados trazados por Bakunin, en Aires de la pampa se estima el Presente un tiempo propicio para acudir tras la redención proletaria. Esta predilección temporal se justifica al estimar que Mariano no planifica su huida para el mañana, sino que por el contrario, le parece adecuado proceder "ahora":

Perucho: (aparte). ¿No manda nada mi teniente?

Mariano: (siempre en último término y en voz baja). Oye, Perucho. ¿Recuerdas lo que te he hablado tantas veces?

Perucho: ¿Raspar la bola ${ }^{21}$ ? Ya lo creo, mi teniente.

Mariano: puede que eso sea esta misma noche. (225)

Recordemos que Aires de la pampa se inicia en "las últimas horas de la tarde" (217), lo cual demuestra que las pretensiones de Mariano se conciben en el Presente, pues el personaje estima que la proximidad de la noche es un momento propicio para ir tras la prosecución de la Libertad.

21 "Raspar la bola" es una expresión coloquial, actualmente en desuso, significa: "escapar, huir, partir, marcharse" (Araya, 308). 
Pablo Fuentes R., El melodrama ácrata Aires de la pampa de Víctor Domingo Silva y su articulación del tiempo según la utopía libertaria de Mijaíl Bakunin / The anarchist melodrama Aires de la pampa by Victor

Domingo Silva and its articulation of the time according to Mijail Bakunin's libertarian utopia, Revista Izquierdas.cl, número 22, enero 2015, ISSN 0718-5049, Santiago de Chile, pp. 1-19

En tal proceso emancipatorio Aires de la pampa contraviene lo propuesto por el canon realista dominante en la época, en cuanto al rol que desempeñaba la figura femenina. Mientras que la escritura decimonónica tradicional concibe lo femenino "un complemento de las determinaciones de los agonistas en espacios muy acotados como el familiar o conyugal" (Pereira, 190), en Aires de la pampa es Chabela quien enfrenta el despotismo de su marido y lidera la Revolución:

Jaime: Y mi mujer va a dar ahora mismo a su marido las llaves del secreter...

Chabela: ¡Eso nunca!

Jaime: ¡Eh! ¡Nunca! ¿Nunca, ha dicho usted?

Chabela: No, Jaime, no tienes derecho.

Jaime: ¿Por qué no? Por lo mismo que usted se niega, tengo ese derecho.

Chabela: ¡Me injurias, Jaime!

Jaime: Su resistencia es casi una confesión, señora...

Chabela: ¡Calla, Jaime, calla!

Jaime: ¡La llave entonces, deme la llave que le pido!

Chabela: ¡Oh Dios mío! No puedo... no debo. No.

Jaime: ¿No? Se niega usted. Se la arrancaré a la fuerza... Deme usted esa llave.

(...)

Chabela: Pégame, como lo has hecho tantas veces... Mátame, si quieres... Pero la llave es mía. (239)

Para entonces Chabela se ha embarcado en un proyecto revolucionario, y no descansará hasta recuperar la dignidad que le ha arrebatado su marido. Este compromiso emancipador explica el convencimiento del personaje a ejercer la violencia física ${ }^{22}$ para recuperar su libertad:

Jaime: (...) ¡ay! De usted, señora, si resulta verdad (Toma el secreter y sale por la izquierda).

Chabela: ¡No! ¡No! ¡No harás eso!... (Sale tras él, se siente ruido de lucha; jadeo; interjecciones; al fin, el ruido seco de un cuerpo que cae. Aparece Chabela desgreñada, con un manojo de cartas en las manos). ¡Ah, Dios mío! ¡Qué alivio! (239-0)

Al comienzo de la segunda escena del Acto Tercero, y tras haber enfrentado a su marido, Chabela corre a los brazos de Mariano para verbalizar su lucha emancipadora:

Chabela: ¡Mariano!

Mariano: ¿Qué?

Chabela: ¡Una cosa horrible!... Mi marido está al cabo de todo. Acabamos de tener una escena espantosa... Quería abrirme el secreter..., cogerme tus cartas... me exigía la llave..., se la negué... me arrebató el secreter para hacerlo pedazos; quise impedirlo por la fuerza..., luchamos, cayó (...) ¡Oh, que angustia, Mariano, no sé cómo he tenido valor! (240).

\footnotetext{
${ }^{22}$ Bakunin reprobaba el uso de la violencia, pues estimaba en ella un "mal enorme y una gran desgracia" (2010, p.102). Para evitar su ejercicio el teórico ácrata recomienda, en primer orden, acabar con el Estado y la Propiedad privada, pues tras la destrucción de ambas instituciones sería innecesario exterminar vidas humanas.
} 
Pablo Fuentes R., El melodrama ácrata Aires de la pampa de Víctor Domingo Silva y su articulación del tiempo según la utopía libertaria de Mijaíl Bakunin / The anarchist melodrama Aires de la pampa by Victor Domingo Silva and its articulation of the time according to Mijail Bakunin's libertarian utopia, Revista Izquierdas.cl, número 22, enero 2015, ISSN 0718-5049, Santiago de Chile, pp. 1-19

Para Bakunin el ejercicio revolucionario sólo adquiere sentido al proyectar sus conquistas en el Porvenir. Será en ese día del mañana en que los pueblos verán nacer "la fraternidad humanitaria triunfante sobre las ruinas de los Estados" (2008, 42). De ahí entonces, la importancia que Mariano le adjudica a ese día venidero:

Mariano: Sí, lo seremos [felices] mientras tú lo quieras; mientras tengas el valor y la resolución, y seas capaz de afrontar el porvenir, de romper las cadenas que te sujetan a ese hombre, y hace de ti una pobre víctima.

(...)

Mariano: (...) Anímate, alma mía, mi pobre palomita dolorida... El porvenir es de los que tiene fe... de los que se aman. (241-2) [Énfasis nuestro]

Ese día del mañana, en que las clases populares serán redimidas, invita a borronear el pasado dando lugar a un imaginario temporal que transita desde el Presente al Porvenir mediante el ejercicio revolucionario. Tal disposición temporal es asumida por los agonistas de Aires de la pampa en los momentos finales del melodrama:

Mariano: Vámonos, vámonos, todo está listo. Borra el pasado en tu recuerdo; de nuestro porvenir respondo yo.

Chabela: ¡Sí, Mariano! ¡Mi Mariano! (242). [Énfasis nuestro]

Antes que caiga el telón, y cuando el lector-espectador espera ansioso que Chabela y Mariano recuperen su libertad y dignidad, Aires de la pampa ofrece un vuelco que da lugar a dudas e incertidumbres mediante un final abierto:

Lalo: (que ha despertado y saca la cabecita por entre las cortinas) ¡Mamá! ¡Mi mamacita!

Chabela: ¡Hijo de mi alma! (Desasiéndose del amante y cayendo de rodillas junto a la camita, abraza a su hijo con un sollozo inmenso. Mariano sigue de pie, inmóvil, en mitad de la alcoba). ¡Mariano, amor mío!... Déjame... toma tus cartas... déjeme morir aquí. (242)

Los finales abiertos no son novedad en la escritura dramática ácrata, pues el texto sólo debe proporcionar los materiales y juicios básicos para que sea el lector-espectador quien construya y de forma a la realidad. Según Pereira Poza sería una abjuración absoluta de los principios libertarios que la escritura dramática imputará una realidad dada de antemano, pues "a quien le corresponde plasmar el nuevo horizonte hacia el cual se ordena el relato es al lector" $(2005,171)$.

\section{Consideraciones finales}

Tal como se ha visto, la vindicación de los sectores populares en Aires de la pampa se ajusta a lo sugerido por la utopía libertaria de Mijaíl Bakunin, en cuanto a la articulación del tiempo. La predilección de los agonista del melodrama por el tiempo Presente queda de manifiesto en los monólogos de Mariano, los cuales dejan trasver que esta disposición 
Pablo Fuentes R., El melodrama ácrata Aires de la pampa de Víctor Domingo Silva y su articulación del tiempo según la utopía libertaria de Mijaíl Bakunin / The anarchist melodrama Aires de la pampa by Victor Domingo Silva and its articulation of the time according to Mijail Bakunin's libertarian utopia, Revista Izquierdas.cl, número 22, enero 2015, ISSN 0718-5049, Santiago de Chile, pp. 1-19

temporal es adecuada para ir tras la prosecución de la Libertad. La instancia revolucionaria es liderada por Chabela, quien a fin de cuentas es la responsable de restituir la condición de sujetos libres y plenos.

Finalmente, aquellas victorias y logros de los sectores populares, según Bakunin, deben proyectarse en un futuro próximo. Estar tarea se resuelve a medias en Aires de la pampa, pues para la escritura dramática ácrata es el lector-espectador quien habrá de dar forma a esa sociedad Ideal del Porvenir, de lo contrario, sería una dimisión absoluta de los principios libertarios entregar una realidad construida de antemano.

Sería interesante proyectar este trabajo a toda la escritura posterior de Víctor Domingo Silva, pues, de este modo, se podría indicar qué fundamentos ácratas subyacen en la escritura narrativa y ensayística del autor. Tal recorrido podría abarcar desde sus novelas más conocidas, por ejemplo, Golondrina de invierno (1912) y El mestizo Alejo (1934); hasta algunos de sus ensayos políticos, tal vez, La tempestad se avecina: el momento internacional latinoamericano (1936).

Del mismo modo, sería interesante analizar la presencia y validez de los cimientos ácratas en la escritura de otros novelistas nacionales que, al igual que Víctor Domingo Silva, también transitaron desde el anarquismo a otras militancias de izquierdas. Tal es el caso de José Santos González Vera, para quien el historiador Sergio Grez Toso ${ }^{23}$ demostró una militancia ácrata en la juventud, en tanto una adultez vinculada a las izquierdas. Esta también es la situación de Manuel Rojas, en cuyas novelas y cuentos podrían pesquisarse huellas e indicios de su breve militancia por el partido socialista ${ }^{24}$.

Por consiguiente, es interesante estudiar, pensar y discutir qué sedimentos ácratas se hallan en la escritura de aquellos novelistas, poetas y dramaturgos nacionales que durante la juventud aprehendieron el credo anarquista para luego, en la adultez, devenir en otras militancias de izquierdas.

Recibido: 4 agosto 2014

Aceptado: 9 noviembre 2014

\section{Bibliografía}

Araya, Guillermo. Sobre arcaísmos del español de Chile. Bulletin Hispanique, 80 (1978), 303-309.

Baigorria, Osvaldo. El amor libre. Eros y Anarquía. Bizkaia: Txalaparta, 2010.

Bakunin, Mijaíl. Estatismo y anarquía. Buenos Aires: Anarres, 2008.

\footnotetext{
${ }^{23}$ Para profundizar en dichas temáticas, léase el trabajo de Grez Toso: "González Vera, de muchacho anarquista a hombre de izquierdas" (2013).

${ }^{24}$ Respecto de la breve militancia de Manuel Rojas en el partido socialista su esposa, Jualianne Clarck, señala: "Manolo fue miembro de ese partido por una semana, hasta que se anunció la candidatura de González Videla" (137).
} 
Pablo Fuentes R., El melodrama ácrata Aires de la pampa de Víctor Domingo Silva y su articulación del tiempo según la utopía libertaria de Mijaíl Bakunin / The anarchist melodrama Aires de la pampa by Victor Domingo Silva and its articulation of the time according to Mijail Bakunin's libertarian utopia, Revista Izquierdas.cl, número 22, enero 2015, ISSN 0718-5049, Santiago de Chile, pp. 1-19

. Ideario anarquista. Buenos Aires: Longseller, 2010.

Capelletti, Ángel. El Anarquismo en América Latina. Caracas: Biblioteca Ayacucho, 1990.

Cortés, Manuel. Anarquismo y lucha antialcohólica en la Guerra Civil Española (19361939). Proyecto hombre 56 (2005), 17-21.

Castelar, Emilio. La revolución religiosa. Madrid: Montaner y Simón, 1880.

Clark, Julienne. ... y nunca te he de olvidar. Memorias de mi vida con Manuel Rojas. Santiago: Catalonia, 2007.

de Sárraga, Belén. 9 conferencias dadas en Santiago. Santiago: Diario Radical La Razón, 1993.

Delemeu, Jean. Historia del milenarismo en occidente. Caracas: Universidad de los Andes, 2001.

Durand, Gilbert. Lo imaginario. Trad. Carme València. Barcelona: del Bronce, 2000.

Fuentes, Pablo. La utopía libertaria según Mijaíl Bakunin y su tratamiento del tiempo histórico, en los textos dramáticos ácratas: ¡Los grilletes!, Suprema Lex, Los cuervos y Los vampiros". Especulo 44 (2010), Madrid: Universidad Complutense. <http://pendientedemigracion.ucm.es/info/especulo/numero44/utopiaba.html>

González Vera, José. Cuando era muchacho. Santiago: Nascimiento, 1951.

Grez Toso, Sergio. La "cuestión social" en Chile. Ideas y debates precursores. Santiago: Dibam, 1995.

- González Vera, de muchacho anarquista a hombre de izquierdas. Anales de la literatura chilena 19 (2013), 183-210.

Gumucio, Rafael. Belén de Sárraga, librepensadora, anarquista y feminista. Polis 9 (2004), 23-55.

Iglesias, Julio. Víctor Domingo Silva: su vida y obra. Santiago: Fantasía, 1960.

Jobet, Julio César. Ensayo crítico de desarrollo económico-social de Chile. Santiago: Universitaria, 1951.

. Recabarren: y los orígenes del movimiento obrero y el socialismo chileno. Santiago: Prensa Latinoamericana, 1973. 
Pablo Fuentes R., El melodrama ácrata Aires de la pampa de Víctor Domingo Silva y su articulación del tiempo según la utopía libertaria de Mijaíl Bakunin / The anarchist melodrama Aires de la pampa by Victor Domingo Silva and its articulation of the time according to Mijail Bakunin's libertarian utopia, Revista Izquierdas.cl, número 22, enero 2015, ISSN 0718-5049, Santiago de Chile, pp. 1-19

Mannheim, Karl. Ideología y utopía. Introducción a la sociología del conocimiento. Trad. Eloy Terron. Madrid: Aguilar, 1958.

Mintz, Franck. Bakunin. Crítica y acción. Buenos Aires: Anarres, 2006.

Molina, Julio. Selva lírica: estudio sobre poetas chilenos. Santiago: Universo, 1917.

Pereira, Sergio. Antología crítica de la dramaturgia anarquista en Chile. Santiago: Universidad de Santiago, 2005.

. La dramaturgia anarquista en Chile. Un discurso de resistencia cultura. Estudios Filológicos 44 (2009), 149-166.

Pinto, Julio. Desgarros y utopías en la pampa salitrera. La consolidación de la identidad obrera en los tiempos de la cuestión social (1890-1923). Santiago: Lom, 2007.

Ricoeur, Paul. Ideología y utopía. Trad. Alberto L. Bixio. Barcelona: Gedisa, 2006.

Silva Endeiza, Víctor. Hacia Allá... Poemas orijinales. Santiago: Imprenta y encuadernación Universitaria, 1905.

Aires de la pampa. La pampa trágica, 217-242. Santiago: Zig-zag. 1938.

Subercaseaux, Benjamín. Víctor Domingo Silva. Paisajes del Centenario (Prólogo). Santiago: Universitaria, 1997.

Varas, José Miguel. Chacón. Santiago: Lom, 1998.

Velasco, Demetrio. Ética y poder político en Mijaíl Bakunin. Bilbao: Universidad de Deusto, 1993.

Venegas, Fernando. Víctor Domingo Silva Endeiza: Una vida sin detenciones. Santiago: Gobierno de Chile, Consejo Nacional del Libro y la Lectura, 2003.

Vitale, Luis. Interpretación marxista de la Historia de Chile. Tomo V. 1967. Santiago: Lom, 1992.

Belén de Sárraga: precursora del feminismo hispanoamericano. Santiago: Ediciones Cesoc, 2000. 